\title{
Development of a Common Research Model for Applied CFD Validation Studies
}

\author{
John C. Vassberg ${ }^{*}$, Mark A. DeHaan ${ }^{\dagger}$ \\ The Boeing Company, Huntington Beach, CA 92647 \\ S. Melissa Rivers ${ }^{\ddagger}$, Richard A. Wahls ${ }^{\S}$ \\ NASA Langley Research Center, Hampton, VA 23681
}

\begin{abstract}
$\underline{\text { Abstract }}$
The development of a wing/body/nacelle/pylon/horizontal-tail configuration for a common research model is presented, with focus on the aerodynamic design of the wing. Here, a contemporary transonic supercritical wing design is developed with aerodynamic characteristics that are well behaved and of high performance for configurations with and without the nacelle/pylon group. The horizontal tail is robustly designed for dive Mach number conditions and is suitably sized for typical stability and control requirements. The fuselage is representative of a wide/body commercial transport aircraft; it includes a wing-body fairing, as well as a scrubbing seal for the horizontal tail. The nacelle is a single-cowl, high by-pass-ratio, flow-through design with an exit area sized to achieve a natural unforced mass-flow-ratio typical of commercial aircraft engines at cruise. The simplicity of this un-bifurcated nacelle geometry will facilitate grid generation efforts of subsequent CFD validation exercises. Detailed aerodynamic performance data has been generated for this model; however, this information is presented in such a manner as to not bias CFD predictions planned for the fourth AIAA CFD Drag Prediction Workshop, which incorporates this common research model into its blind test cases. The CFD results presented include wing pressure distributions with and without the nacelle/pylon, $\mathrm{ML} / \mathrm{D}$ trend lines, and drag-divergence curves; the design point for the wing/body configuration is within $1 \%$ of its max-ML/D. Plans to test the common research model in the National Transonic Facility and the Ames 11-ft wind tunnels are also discussed.
\end{abstract}

\subsection{Introduction}

The genesis of a common research model was motivated by a number of interested parties asking NASA to help develop contemporary experimental databases for the purpose of validating specific applications of computational fluid dynamics (CFD). For example, the organizing committee of the international AIAA CFD Drag Prediction Workshop (DPW) series ${ }^{1}$ is in need of new types of high-quality detailed experimental data in order to better understand and help improve issues of numerical flow field

\footnotetext{
${ }^{*}$ Boeing Technical Fellow, Associate Fellow AIAA.

${ }^{\dagger}$ Principal Engineer/Scientist

* Aerospace Engineer, Configuration Aerodynamics Branch, Senior Member AIAA

$\S$ Project Scientist, Subsonic Fixed Wing / Fundamental Aeronautics Program, Associate Fellow AIAA
} 
simulations as related to the accuracy of drag and moment predictions. Due to the success of the DPW series, other groups, such as the computational stability and control (COMSAC) community, are interested in organizing similar workshops, and they too have a need for very specific high-quality experimental data needed to validate CFD predictions on a wide variety of items such as control-surface effectiveness, trim drag, wind-tunnel (low) to flight (high) Reynolds number effects, and stability derivatives. There is also a benefit for a common model to be tested at numerous wind tunnels to help anchor the experimental measurements and correction methods between facilities.

NASA's Subsonic Fixed Wing (SFW) Project within the Fundamental Aeronautics (FA) Program has established a suite of discipline-oriented technical working groups (TWG) as a way to facilitate the dissemination of technology, and coordinate research and development within and outside of NASA. A TWG is not steering or advisory committee, but rather a vehicle to transfer information and promote collaboration. The primary focus of a TWG is on basic/foundational research and discipline tools and technologies (e.g., aerodynamics) that tend to be at a cross-cutting, pre-competitive state, but with an eye towards multidisciplinary subsystem and system-level activities.

The SFW Aerodynamics TWG in particular was formed and held its first meeting in January 2007. The SFW Aerodynamics TWG membership currently consists of technical leaders from US industry and government; in particular meeting participants have included personnel from Boeing, Lockheed-Martin, Northrop-Grumman, Gulfstream, Cessna, Hawker-Beechcraft, Pratt and Whitney, Air Force, Navy, and NASA. Among the many topics discussed at the initial meeting was the idea of new benchmark experiments on publicly available geometries suitable for cooperative assessment and validation of aerodynamic prediction tools, framed much like the successful DPW series. Specific input and general comments on this topic were received by the SFW Project Aerodynamics leadership through June 2007, and shared and discussed within the TWG. In addition to direct input from the TWG members, the input and experience of international DPW Organizing Committee and discussion of next steps from the DPW workshops and AIAA conference summary sessions were considered. Additionally, thoughts on new initiatives along these lines from AIAA Applied Aero Technical Committee and the NATO RTO Air Vehicle Technology groups were also considered.

Most conversation within the TWG focused on an open geometry high-speed wing configuration building off lessons learned during the DPW series but defining a new relevant geometry, acquiring new data rather than relying on existing limited data, and ensuring a focus beyond cruise drag to include pitching-moment through a full and relevant angle-of-attack range; additionally, wing-tail interaction was considered important to address. Consideration was given to defining and focusing on a low-speed high-lift or stability and control centric activity; in the end, it was felt such activities could flow from an initial high-speed performance centric activity and resulting geometry if such future activities were considered up front in configuration design. One of the challenges of the DPW organizing committee, and honestly any such endeavor, was identifying a modern, relevant geometry and having that geometry be publicly available this challenge tends to drive one towards the compromise of accepting older geometries 
in order to share widely and openly. In the case of the DPW, the newest geometry was the DLR-F6 designed in the 1980s with a cruise Mach number of 0.75. As a result, the TWG set out to characterize a new and relevant open geometry configuration to be designed with state-of-the-art tools, and designed with physics and CFD validation as a higher priority than minimizing drag - this philosophy drives some of the design trades/features of the new configuration. This new configuration has come to be known as the NASA Common Research Model (CRM).

The TWG addressed and debated features that characterize the CRM configuration and model. First was discussion of a conventional, tube/wing configuration versus a hybrid or blended wing/body configuration. It was felt that a conventional configuration would be sufficiently challenging and relevant for aerodynamic prediction validation, based in no small part on the challenges observed in the DPW series. Additionally, a conventional configuration would likely ensure broader participation across industry at this juncture, and that aerodynamic prediction lessons learned, for the most part, would be applicable to hybrid wing/body configurations as well. Second, there was discussion of a high-wing versus low-wing configuration; for similar reasons, the CRM is a low-wing configuration. Third, it was decided to include a nacelle/pylon installation; however, it was also decided to ensure a pertinent clean-wing design to enable study of a simpler geometry that maintains relevant physics. It was recognized that today's state-of-the-art design tools are more than sufficient to enable a fully integrated/coupled design that would enable minimized drag, but this step back in design philosophy was taken to enable a simpler but still relevant wing-only case. Along similar lines, it was decided to forgo flap-support fairings and winglets, though future integration of each should be considered. Additionally, trailing-edge concepts to reduce drag, generally including varying degrees of bluntness, are also not included in the name of simplicity; it was acknowledged that an entire line of study could center on trailing-edge design and modeling. Finally, a design Mach number of 0.85 was established; there was much discussion on this topic with most interest falling between 0.80 and 0.90 .

With this background, The Boeing Company took the lead on detailed aerodynamic design of the CRM, while the NASA FA/SFW Project took the lead on model design, fabrication, and testing of the CRM. The TWG continues to provide overarching recommendations on overall direction and input at the technical detail level. The DPW Organizing Committee is providing detailed technical input and providing the framework and forum for an international assessment of CFD-based aerodynamic prediction tools utilizing this new configuration.

This paper is organized as follows. Section 2 provides the general layout of the full-scale aircraft being represented by the CRM. Section 3 discusses the design and optimization results of the CRM without divulging absolute performance metrics per aforementioned reasons. Section 4 gives some details and status on the wind-tunnel model design and fabrication, as well as provides a discussion of the envisioned, initial test plans to acquire unique low and high Reynolds number data with modern test and measurement capabilities that will be released into the public domain. Tables are embedded within the body of text, while all figures are appended to the end of this report. 


\subsection{General Layout and Detailed Geometry Description}

After much discussion, the SFW TWG agreed that the CRM should be based on a transonic transport configuration designed to fly at a cruise Mach number of $\mathrm{M}=0.85$ with a nominal lift condition of $\mathrm{C}_{\mathrm{L}}=0.50$, and at a Reynolds number of $\mathrm{Rn}=40$ million per reference chord. They also specified that the wing should have an aspect-ratio of $\mathrm{AR}=9.0$, and a taper-ratio of $\lambda=0.275$. Additionally, the span should be sized accordingly to integrate into an existing fuselage model. Accommodating these basic guidelines, the derived reference quantities of the full-scale vehicle are given in Table 1. Note that Sref is based on Wimpress area but the trap-wing area is also given. The resulting wing planform is shown in Figure 1. This figure illustrates the side-of-body nominally at $10 \%$ semispan and the yehudi break occurs at the $37 \%$ station. Table 2 provides detailed airfoil information of the CRM wing at its 21 defining stations. These data correspond to a nominal 1-G wing at cruise. The trailing-edge (TE) thickness is non-zero to accommodate a minimum-gauge model fabrication constraint of 0.014 inches; at the wingtip this results in a $0.48 \%$ thick TE base. The data of Table 2 are plotted in Figures 2-6. Figure 2 depicts a side-view of the airfoil stack as rigged in the fuselage reference plane. Figures 3-4 illustrate the non-dimensional and dimensional maxthickness distributions across the wing, respectively; the average non-dimensional thickness of the exposed wing is about 10.8\%. Figure 5 gives the max-camber distribution. Note that the outboard wing carries supercritical airfoil sections with about $1.5 \%$ camber. Figure 6 shows the wing's twist distribution and indicates that the wing is washed out about 8 degrees from side-of-body to wingtip. Figures 7-8 provide chordwise thickness and camber distributions for airfoil geometries at the yehudi break $(37 \%$ semispan) and on the outboard wing (75\% semispan), respectively. Although similar geometric details for the fuselage, horizontal-tail, and nacelle/pylon components are not included in this report, Figures 9-10 illustrate their integration into the wing/body/nacelle/pylon/horizontal-tail (WBNPH) configuration of the CRM.

\begin{tabular}{|c|c|c|}
\hline \multicolumn{3}{|c|}{ Table 1: Reference Quantities for the CRM. } \\
\hline Sref & $594,720.0 \mathrm{in}^{2}$ & $4,130.0 \mathrm{ft}^{2}$ \\
\hline Trap-Wing Area & $576,000.0 \mathrm{in}^{2}$ & $4,000.0 \mathrm{ft}^{2}$ \\
\hline Cref & $275.80 \mathrm{in}$ & \\
\hline Span & $2,313.50 \mathrm{in}$ & $192.8 \mathrm{ft}$ \\
\hline Xref & $1,325.90 \mathrm{in}$ & \\
\hline Yref & $468.75 \mathrm{in}$ & \\
\hline Zref & $177.95 \mathrm{in}$ & \\
\hline$\lambda$ & 0.275 & \\
\hline$\Lambda_{\mathrm{C} / 4}$ & $35^{\circ}$ & \\
\hline$A R$ & 9.0 & \\
\hline
\end{tabular}


Table 2: Detailed Geometric Data for the CRM Wing.

\begin{tabular}{|c|c|c|c|c|c|c|c|c|c|}
\hline \multicolumn{10}{|c|}{ NASA CRM-05a } \\
\hline \multicolumn{2}{|c|}{$\begin{array}{r}\text { sref } \\
594,720.0\end{array}$} & $\begin{array}{r}\text { cref } \\
275.80\end{array}$ & $\begin{array}{r}\text { xref } \\
1,325.90\end{array}$ & $\begin{array}{r}\text { yref } \\
468.75\end{array}$ & $\begin{array}{r}\text { zref } \\
177.95\end{array}$ & $\begin{array}{r}\mathrm{b} / 2 \\
1,156.75\end{array}$ & $\begin{array}{l}\text { ar } \\
9.0\end{array}$ & $\begin{array}{l}\text { sweep } \\
35.0\end{array}$ & $\begin{array}{l}\text { taper } \\
0.275\end{array}$ \\
\hline ns & eta. & xle & yle & zle & twist & c-plan & $t / c$ & cambr/c & $d z / c-t e$ \\
\hline 1 & 0.00 & 904.294 & 0.000 & 174.126 & 6.7166 & 536.181 & 0.1542 & 0.0003 & 0.0010 \\
\hline 2 & 0.10 & 989.505 & 115.675 & 175.722 & 4.4402 & 468.511 & 0.1380 & 0.0012 & 0.0011 \\
\hline 3 & 0.15 & 1032.133 & 173.513 & 176.834 & 3.6063 & 434.674 & 0.1280 & 0.0018 & 0.0012 \\
\hline 4 & 0.20 & 1076.030 & 231.351 & 177.361 & 3.0131 & 400.835 & 0.1198 & 0.0025 & 0.0013 \\
\hline 5 & 0.25 & 1120.128 & 289.188 & 177.912 & 2.2419 & 366.996 & 0.1137 & 0.0037 & 0.0014 \\
\hline 6 & 0.30 & 1164.153 & 347.026 & 178.886 & 1.5252 & 333.157 & 0.1092 & 0.0061 & 0.0016 \\
\hline 7 & 0.35 & 1208.203 & 404.864 & 180.359 & 0.9379 & 299.317 & 0.1060 & 0.0085 & 0.0017 \\
\hline 8 & 0.37 & 1225.820 & 427.999 & 181.071 & 0.7635 & 285.782 & 0.1052 & 0.0095 & 0.0018 \\
\hline 9 & 0.40 & 1252.246 & 462.701 & 182.289 & 0.4285 & 277.288 & 0.1038 & 0.0107 & 0.0019 \\
\hline 10 & 0.45 & 1296.289 & 520.539 & 184.904 & -0.2621 & 263.130 & 0.1019 & 0.0122 & 0.0020 \\
\hline 11 & 0.50 & 1340.329 & 578.377 & 188.389 & -0.6782 & 248.973 & 0.1000 & 0.0136 & 0.0021 \\
\hline 12 & 0.55 & 1384.375 & 636.214 & 192.736 & -0.9436 & 234.816 & 0.0988 & 0.0146 & 0.0022 \\
\hline 13 & 0.60 & 1428.416 & 694.052 & 197.689 & -1.2067 & 220.658 & 0.0978 & 0.0152 & 0.0023 \\
\hline 14 & 0.65 & 1472.458 & 751.890 & 203.294 & -1.4526 & 206.501 & 0.0970 & 0.0154 & 0.0025 \\
\hline 15 & 0.70 & 1516.504 & 809.727 & 209.794 & -1.6350 & 192.344 & 0.0962 & 0.0158 & 0.0027 \\
\hline 16 & 0.75 & 1560.544 & 867.565 & 217.084 & -1.8158 & 178.186 & 0.0958 & 0.0161 & 0.0029 \\
\hline 17 & 0.80 & 1604.576 & 925.402 & 225.188 & -2.0301 & 164.029 & 0.0955 & 0.0162 & 0.0031 \\
\hline 18 & 0.85 & 1648.616 & 983.240 & 234.082 & -2.2772 & 149.872 & 0.0953 & 0.0161 & 0.0034 \\
\hline 19 & 0.90 & 1692.659 & 1041.078 & 243.635 & -2.5773 & 135.714 & 0.0952 & 0.0155 & 0.0038 \\
\hline 20 & 0.95 & 1736.701 & 1098.915 & 253.691 & -3.1248 & 121.557 & 0.0951 & 0.0127 & 0.0042 \\
\hline 21 & 1.00 & 1780.737 & 1156.753 & 263.827 & -3.7500 & 107.400 & 0.0950 & 0.0009 & 0.0048 \\
\hline
\end{tabular}

\subsection{Aerodynamic Design}

Based on input from the SFW TWG, a contemporary supercritical transonic wing has been designed for the CRM. The fuselage is representative of a wide-body commercial transport aircraft; it includes a wing-body fairing, as well as a scrubbing seal for the horizontal tail. In addition to the geometric criteria discussed in the previous section, the TWG requested a wing design suitable for a flight condition of $0.85 \mathrm{M}, \mathrm{C}_{\mathrm{L}}=0.5$, and a chord Reynolds number of 40 million. Furthermore, this wing design should exhibit fairly high performance over a reasonable neighborhood of the design point (i.e., not be a single-point design). For example, between step climbs, a typical commercial transport will experience lift coefficients that range on the order of $+/-0.02$ about its nominal cruise point, as the aircraft burns fuel at a given altitude. When a certain amount of fuel is burned at that altitude, the aircraft will climb to the next allowable discrete altitude, and the process repeats. Additionally, the wing design must accommodate a 1.3-Gs to buffet criteria; and the list of requirements continues. Another attribute worth noting is that a typical airline will fly aircraft at a higher Mach number than that of the optimum range condition; burning up to $1 \%$ more fuel. While range factor is also influenced by the specific fuel consumption of the engines and the aircraft structural weight, in this context where only aerodynamic performance is known, we use maximum ML/D as a surrogate for maximum range. Hence, we seek a wing whose design-point ML/D is within $1 \%$ of its maximum value. An additional requirement of the TWG was that the aerodynamic characteristics of the configuration with and without nacelle/pylon (NP) group be well behaved. The two primary drivers for the requirement of a good wing/body (WB) design are that, 1) it provides a simpler case for validation studies, and 2) it is more representative of low-wing configurations with aft-fuselage mounted engines, such as business jet aircraft. Hence, the approach taken here is to first develop a high- 
performance wing in the presence of only the fuselage, then after the fact, integrate the nacelle/pylon group without introducing undesirable installation effects. This represents a step backward relative to our current design practices for under-wing mounted engines, but nonetheless this approach was required to best satisfy the requirements of the TWG.

SYN107 was utilized to facilitate the rapid design and optimization of the CRM wing in the presence of the fuselage. (SYN107 is a CFD-based synthesis code developed by Jameson $^{2}$.) Numerous multipoint optimizations were conducted that included a range of Mach and lifting conditions. For example, a typical 5-point optimization included $\left(\mathrm{M}, \mathrm{C}_{\mathrm{L}}\right)$ values of: $(0.85,0.50),(0.85,0.48),(0.85,0.52),(0.84,0.50)$, and $(0.86,0.50)$. These optimizations were conducted with constraints on wing thickness and spanload distributions. The objective function of these optimizations included a blend of weighted drag minimization and target pressures. Once these optimizations were completed, the resulting wing geometry was extracted from the SYN107 grid and projected onto the 21 defining stations of Table 2. Later, this wing definition was surfaced to create an IGES representation of the geometry, and delivered to NASA for the purpose of model design.

Figures 11-13 provide pressure distributions for the CRM wing at its design point, based on an OVERFLOW solution of the WB configuration. (OVERFLOW is a ReynoldsAveraged Navier-Stokes CFD method based on overset grids developed by NASA ${ }^{3}$.) Figure 12 provides a top/bottom view of the wing upper/lower surface isobars. Note that the upper-surface shock system in the mid-span region is swept essentially along a constant $\mathrm{X} / \mathrm{C}$ element line, while on the outboard wing reduces in strength. This character can also be seen in the detailed pressure distributions provided by Figure 13 at the slightly-off-design condition of $\mathrm{C}_{\mathrm{L}}=0.49$ and $0.85 \mathrm{M}$.

A fairly comprehensive set of flight conditions surrounding the design point were also analyzed. These OVERFLOW CFD results are given in Figures 14-16. Figure 14 shows the ML/D trend lines for five different Mach numbers as a function of lift coefficient. The large blue dot at $\mathrm{C}_{\mathrm{L}}=0.50$ on the $\mathrm{M}=0.85$ trend line highlights the design point. Note that by observation, it appears that the maximum ML/D point occurs somewhere near $\mathrm{C}_{\mathrm{L}}=0.47$ and $\mathrm{M}=0.85$. This max-ML/D point is shown as the maroon dot in Figures 15-16. Also provided in these figures is the $99 \%$ max-ML/D contour line for reference. Note that the CRM design point falls within this contour. Figure 15 depicts three drag-rise curves for $\mathrm{C}_{\mathrm{L}}=[0.40,0.45,0.50]$. Figure 16 shows a representative point (green dot) where an airline might trade 1\% fuel burn for an additional 0.006 in cruise Mach number. In fact, one should not read too much into this data as it is subject to change with the inclusion of the remaining nacelle/pylon and horizontal-tail components. These characteristics are included here for the primary purpose to illustrate that the wing design is fairly robust for a wide range of flow conditions.

As a final note regarding the CRM wing design, Figures 17-18 provide the installation effects of the nacelle/pylon group on the wing pressures, as computed by TRANAIR ${ }^{4}$. The nacelle developed for the CRM is a single-cowl, flow-through design with an exit area sized to achieve a natural unforced mass-flow-ratio typical of commercial aircraft engines at cruise. The simplicity of the un-bifurcated internal geometry is partially 
motivated to minimize grid-generation efforts for future CFD validation exercises. Figure 17 illustrates the wing upper-surface isobars with and without the nacelle/pylon installed. Figure 18 provides the chordwise pressure distributions at eight span stations for the configuration with and without the nacelle/pylon. The solid curves correspond to the wing/body/nacelle/pylon solution, while the dashed curves represent the wing/body results. Note that the stations at $27.0 \%$ and $38.6 \%$ semispan straddle the nacelle/pylon location. With focus on these two subplots, one can see that the nacelle/pylon induces additional up-wash on the inboard wing leading edge, while reducing it outboard. The inboard influence extends all the way to the fuselage, while the outboard perturbations quickly decay with increasing semispan location; for all practical purposes, this influence is insignificant beyond mid-span. The TRANAIR and OVERFLOW solutions both confirm that the SYN107 optimizations have produced a robust and high-performance wing design.

The horizontal tail has been designed with consideration given to be robust at dive Mach number conditions; it is suitably sized for typical stability and control requirements. The general layout of the horizontal tail has a trapezoidal planform with a quarter-chord sweep of $37^{\circ}$, a taper-ratio of 0.35 , a mean-aerodynamic chord of 184.7 inches, a span of 840 inches, and an area of $1,000 \mathrm{ft}^{2}$. The horizontal is defined with two symmetric airfoil sections, a 10\%-thick section at the plane-of-symmetry and an 8\%-thick airfoil at its tip. The incidence of the tip section is twisted $3^{\circ}$ leading-edge up relative to the root airfoil, to provide adequate wash-out for this downward-lifting surface. In addition to the airfoil stack, a hinge line is specified for the horizontal such that its contact with the side of fuselage remains sealed. Figure 19 provides pressure distributions for the horizontal tail at the three incidence settings of $\mathrm{iH}=\left\{-2.0^{\circ}, 0.0^{\circ},+2.0^{\circ}\right\}$. For reference, the WBNPH configuration with a center-of-gravity position at about $28 \%$ mean-aerodynamic chord is in static trim for an $\mathrm{iH}=0.0^{\circ}$ per the TRANAIR solutions of Figure 19.

\subsection{Plans for Wind-Tunnel Testing}

In July 2008, NASA awarded a contract for the detailed design and fabrication of new wind tunnel model hardware for the CRM configuration. New wing, nacelle/pylon group, and horizontal-tail components as described above will be combined with an existing fuselage to enable tests of WB and WBNP configurations with and without a horizontal tail; three tail incidence angles will be available to determine the trimmed condition. The model will include 303 wing pressures located at 8 spanwise stations, and 6 pressures in the left-hand nacelle; note that the wing pressures will be distributed between left and right wings in such a manner as to minimize any differences due to asymmetric static aeroelastic twist or bending. The model will be mounted using an existing upper-swept-blade support that enters the fuselage in the location of a vertical tail, but is enlarged relative to a scaled vertical tail in order to safely handle model loads. Currently, the new model parts are scheduled for delivery in the $1^{\text {st }}$ quarter of calendar year 2009. 
As mentioned before, the CRM and associated test plans evolved from a combination of several goals/objectives: 1) a new relevant geometry, 2) acquire new data with modern test and measurement capabilities rather than relying on existing limited data, and 3) ensuring a focus beyond cruise drag to include pitching-moment through a full and relevant angle-of-attack range. The new geometry is directly addressed by the model itself as described above. A focus including but not limited to cruise drag is ensured by inclusion of tails to generate moment increments, and test plans to include a full range of angle-of-attack. New data acquired with modern test and measurement capabilities can imply many things, but here specifically addresses: 1) acquisition of data across a large range of Reynolds number from conventional wind tunnel levels to flight, and 2) acquisition of data on an aircraft configuration beyond standard force/moment and surface pressure data. The high Reynolds number data will be sufficiently high to ensure fully turbulent flow from the leading-edge; the intent is to eliminate the computational question of how to simulate fixed or natural transition and any question about the influence or intrusiveness of a selected transition fixing method on wind tunnel results. Data acquisition beyond the conventional indicates a desire to acquire skin friction data, and off-body mean and unsteady data for comparison to computational simulations with the goal to enable improvements in predictions.

To address these goals, it is currently planned for the CRM to be tested in the NASA Ames 11-ft transonic wind tunnel and the NASA National Transonic Facility (NTF) at Langley. The NTF will include cryogenic runs to acquire high Reynolds number data, while the 11-ft facility will provide skin friction and off-body data at a lower Reynolds number. The chord Reynolds number will be 5 million in the Ames 11-ft. and will range from 3 to 30 million in NTF. The test matrix in each facility will include a range of Mach numbers from 0.70 to 0.92 with focus on the design point of $0.85 \mathrm{M}$. The configurations to be tested include WB, the WBNP, and the WBH with the horizontal-tail at three different incidence settings. The plan is to acquire force, moment, and surface pressure, plus wing deformation under load in each facility. In the Ames 11-ft, off-body flowfield velocities will be collected via Particle Image Velocimetry (PIV), and skin friction data collected via a fringe imaging skin-friction interferometry (FISFI) method; each of these methods has been used previously in the facility. The current test plan includes approximately 4,500 points in the NTF and nearly 2,100 points in the Ames 11 - $\mathrm{ft}$ test; note that the specialized data to be acquired in the 11-foot requires more time on point than conventional data. In order to connect the datasets between tunnels, a common Reynolds number and equivalent aeroelastic shape must be ensured. Figure 20 provides an operating chart for the Ames 11-ft wind tunnel. Included in this figure is the selected operating condition for the CRM, depicted by the yellow dot at $0.85 \mathrm{M}$ and Reynolds number of approximately 8 million per foot, or 5 million based on the mean aerodynamic chord. Conditions in the NTF air mode of operation will also provide a chord Reynolds number of 5 million, at essentially the same dynamic pressure of 1,325 psf, thus providing consistent static aeroelastic deformation of the model as well.

The NTF is able to independently control Mach number, Reynolds number, and dynamic pressure through independent control of pressure, temperature, and velocity; this capability enables study of pure Reynolds number, compressibility, or static aeroelastic 
effects. Holding Mach number and $\mathrm{Q} / \mathrm{E}$ constant, where $\mathrm{E}$ is the model material modulus of elasticity and is a function of temperature, while varying only Reynolds number enables isolation of pure Reynolds number effects. Similarly, an a pure aeroelastic effect can be obtained in the NTF by keeping the Mach and Reynolds number constant while varying only $\mathrm{Q} / \mathrm{E}$. Table 3 in conjunction with Figures 21-22 illustrate the operating conditions planned for the CRM in order to obtain pure Reynolds-number effects as well as pure aeroelastic effects. Figure 22 is a close-up of Figure 21 in the pertinent operating range. Note that between the first (yellow dot) and second (green dot) operating conditions, Q/E is held at a constant value of $0.349 \times 10^{-6}$, while the Reynolds number increases from 5 to 19.8 million. Between the second and third (light-blue dot) conditions, the Reynolds number is held at a constant value of 19.8 million, while $\mathrm{Q} / \mathrm{E}$ varies from 0.349 to $0.507 \times 10^{-6}$. The higher value of $\mathrm{Q} / \mathrm{E}$ will cause a higher deflection (bending and twist) of the wing at a given $\mathrm{C}_{\mathrm{L}}$. Finally, another pure Reynolds-number sweep is performed between the third and fourth (dark-blue dot) operating conditions.

Currently, the NTF test is planned for the $2^{\text {nd }}$ quarter of calendar year 2009 with the Ames 11-foot test to occur in the first half of government fiscal year 2010. In addition to the currently planned tests for the Ames 11-ft and the NTF, it is envisioned that the CRM can be made available for cooperative tests sponsored by other organizations (beyond NASA) in other facilities around the world that world that can add additional, and ideally unique, data to the public dataset for the CRM configuration.

Table 3: CRM Operating Conditions at $0.85 \mathrm{M}$ in the NTF with Key Codes for Figures 21-22.

\begin{tabular}{|c|c|c|c|c|c|}
\hline Key & $\mid \begin{array}{c}R_{n_{c}} \\
\left(10^{\circ} f t\right)\end{array}$ & $\begin{array}{c}T_{t} \\
\left({ }^{\circ} F\right)\end{array}$ & $\underset{\text { (pola) }}{P_{t}}$ & $\underset{(p 8 f)}{Q}$ & $\begin{array}{c}\text { Q/E } \\
\left(10^{-6}\right)\end{array}$ \\
\hline & 5.0 & 100 & 29.2 & 1,325 & 0.349 \\
\hline & 19.8 & -250 & 28.9 & 1,310 & 0.349 \\
\hline & 19.8 & -182 & 43.7 & 1,886 & 0.507 \\
\hline & 30.0 & -250 & 43.9 & 1,986 & 0.503 \\
\hline
\end{tabular}

\section{$\underline{5.0 \text { Summary }}$}

A contemporary transonic supercritical wing has been developed for the NASA CRM wing/body/nacelle/pylon/horizontal-tail configuration. Aerodynamic characteristics of the CRM wing design are well behaved and of high performance for configurations with and without the nacelle/pylon group. The horizontal tail is robustly designed for dive Mach number conditions and is suitably sized for typical stability and control requirements. The fuselage is representative of a wide/body commercial transport aircraft; it includes a wing-body fairing, as well as a scrubbing seal for the horizontal tail. The nacelle is a large-diameter single-cowl flow-through design with an exit area sized to achieve a natural unforced mass-flow-ratio typical of commercial aircraft engines at 
cruise. The simplicity of this un-bifurcated nacelle geometry will facilitate grid generation efforts of subsequent CFD validation exercises. Detailed aerodynamic performance data has been generated for this model; however, this information is presented in such a manner as to not bias CFD predictions planned for the fourth AIAA CFD Drag Prediction Workshop, which incorporates this common research model into its blind test cases. The CFD results presented include wing pressure distributions with and without the nacelle/pylon, ML/D trend lines, and drag-divergence curves; the design point for the wing/body configuration is within $1 \%$ of its max-ML/D. Plans to test the common research model in the NTF and the Ames 11-ft wind tunnels are also discussed. The time tables of these wind-tunnel tests facilitate the blind test cases of DPW-IV based on the CRM, and yet, will allow comparisons of the CFD results with some experimental data shortly after this workshop is conducted.

\subsection{Acknowledgements}

The aerodynamic design of the CRM wing, horizontal tail, and nacelle/pylon group is provided by The Boeing Company. The design, fabrication, and testing of the CRM wind-tunnel model is being funded by the NASA Fundamental Aeronautics Program. The first author thanks Professor Antony Jameson of Stanford University for his collaboration and contributions to this project. The CRM nacelle/pylon design and integration were conducted by Peg Curtin and Ben Rider of Boeing Commercial Aircraft; Ben Rider also provided the TRANAIR results shown herein.

\section{References}

1. AIAA CFD Drag Prediction Workshop website: http://aaac.larc.nasa.gov/tsab/cfdlarc/aiaa-dpw/ email: dpw@cessna.textron.com/

2. A Jameson \& JC Vassberg. Computational Fluid Dynamics for Aerodynamic Design: Its Current and Future Impact. AIAA Paper 2001-0538, Reno, NV, 2001.

3. PG Buning, DC Jespersen, TH Pulliam, WM Chan, JP Slotnick, SE Krist, \& KJ Renze. OVERFLOW User's Manual, Version 1.81. NASA Report, NASA Langley Research Center, Hampton, VA, 1999.

4. SS Samant, JE Bussoletti, FT Johnson, RH Burkhart, BL Everson, RG Melvin \& DP Young. TRANAIR: A Computer Code for Transonic Analysis of Arbitrary Configurations. AIAA Paper 87-0034, Reno, NV, January, 1987. 
NASA Common Model

Sref $=594,720.0$, Cref $=275.8, \quad b=2,313.5, \quad$ Xref $=425.9, \quad A R=9.0$

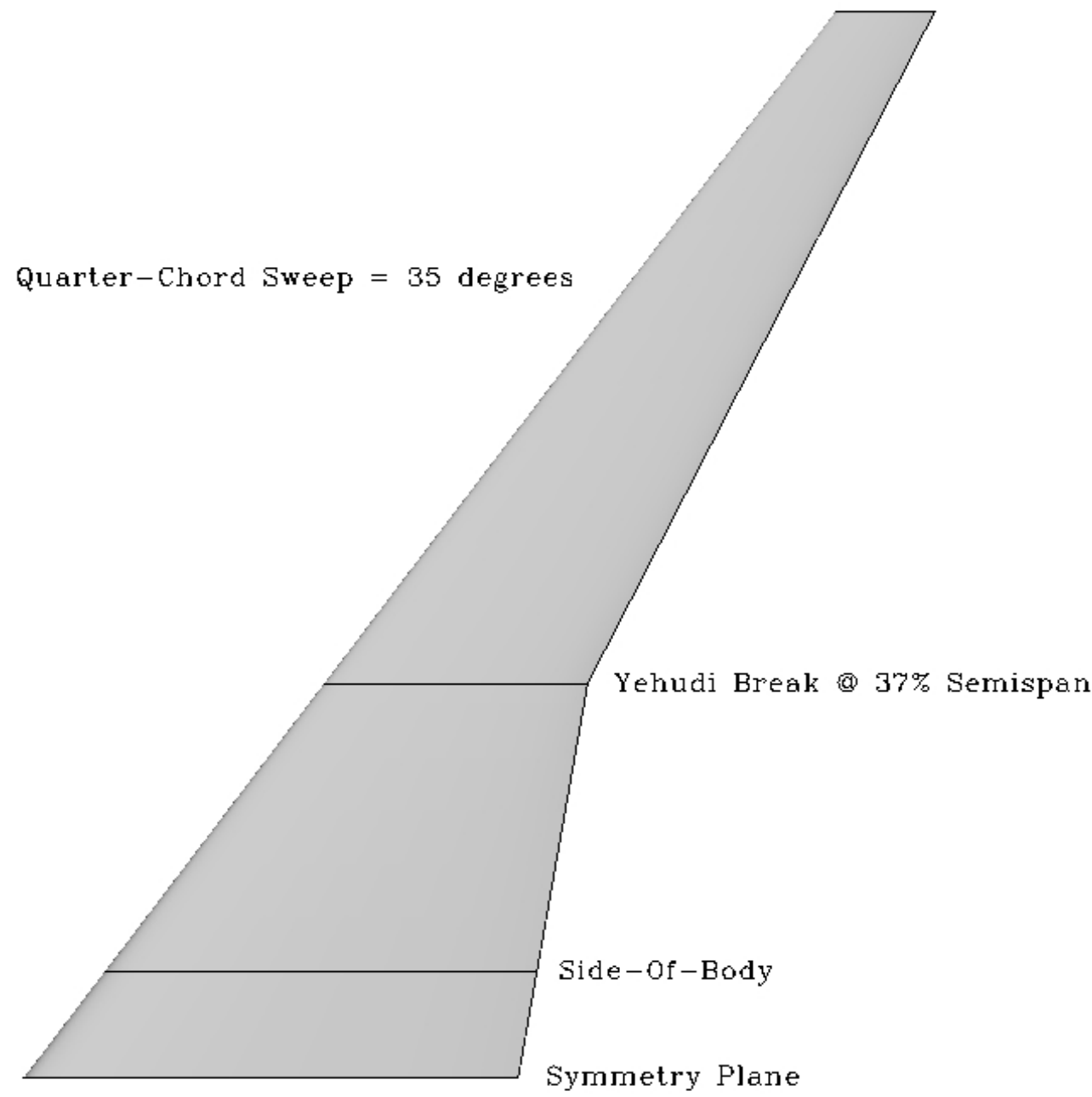

Figure 1: Full-Scale Planform of the CRM Wing.

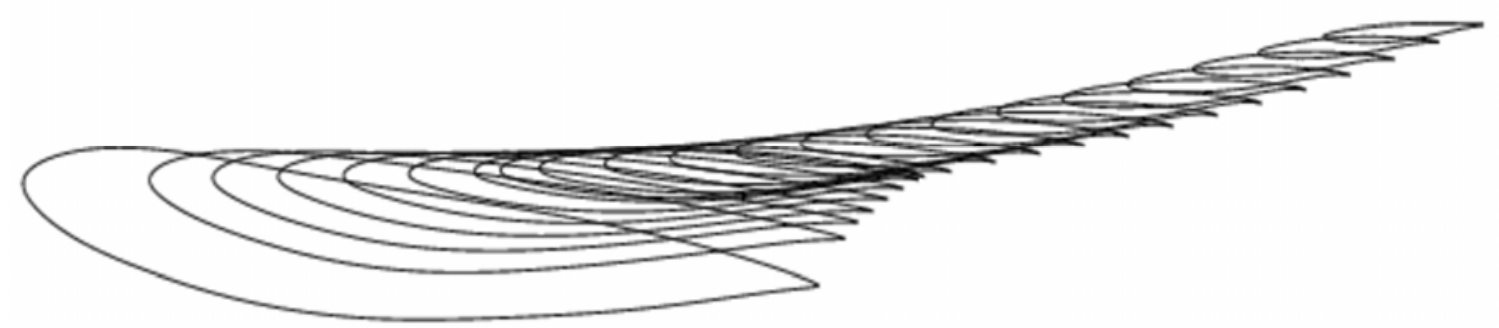

Figure 2: Airfoil Stack for the CRM Wing. 


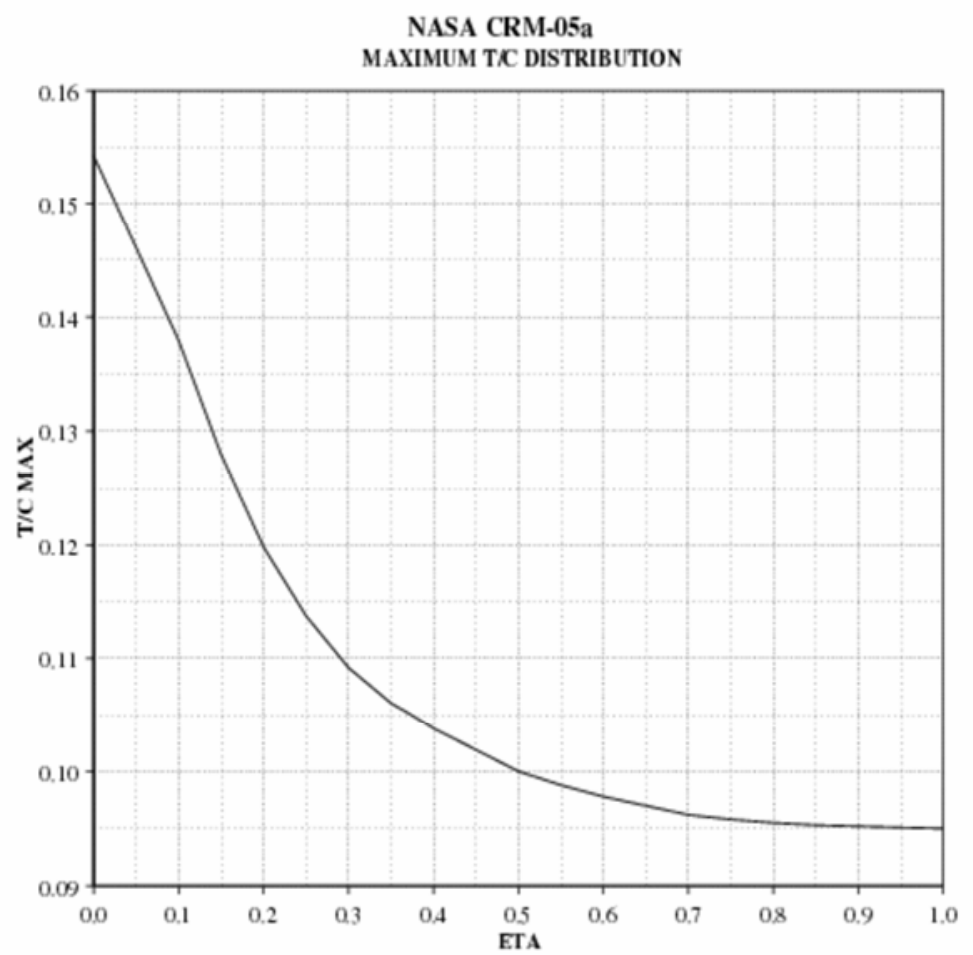

Figure 3: Non-Dimensional Thickness Distribution of the CRM Wing.

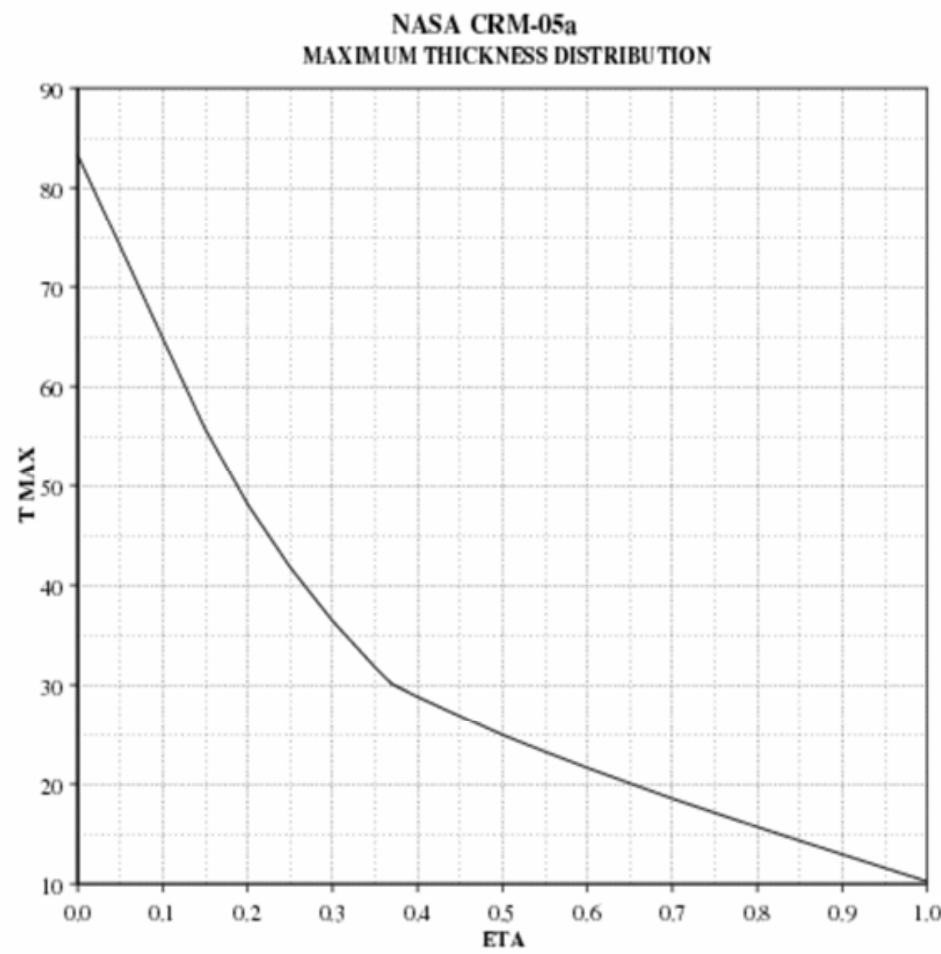

Figure 4: Dimensional Thickness Distribution of the CRM Wing. 


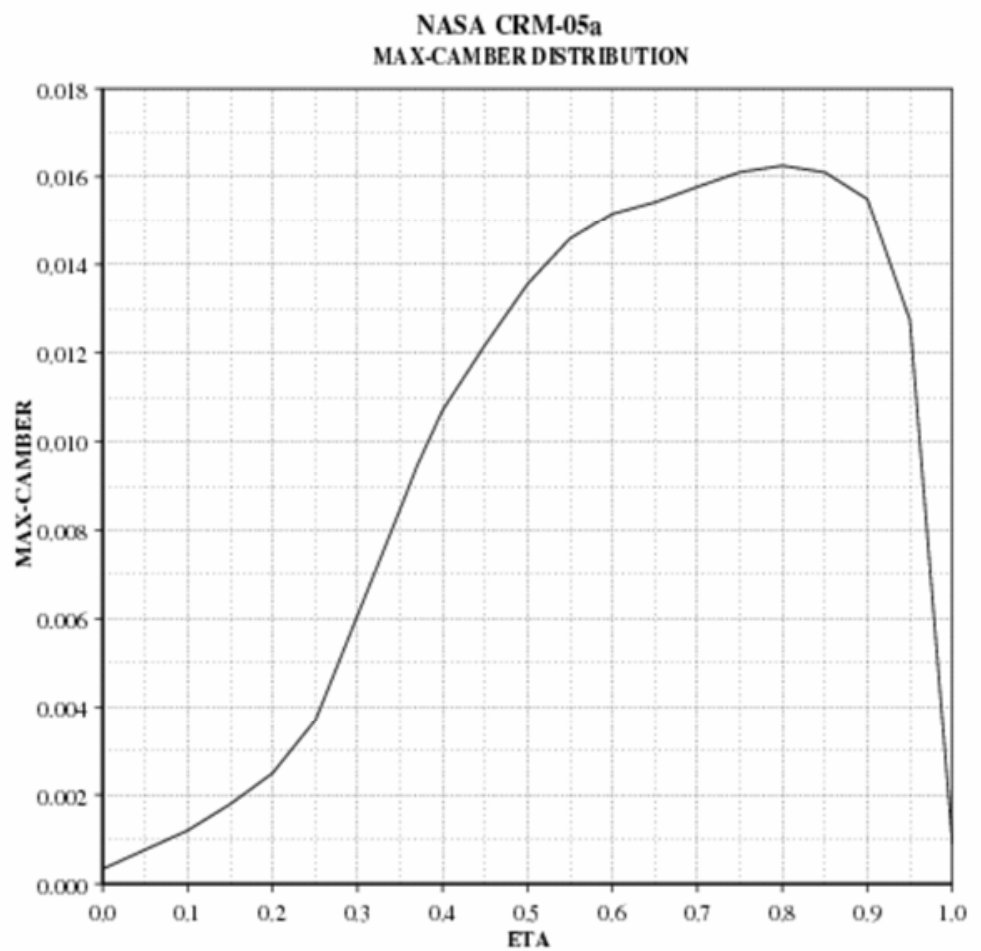

Figure 5: Max-Camber Distribution of the CRM Wing.

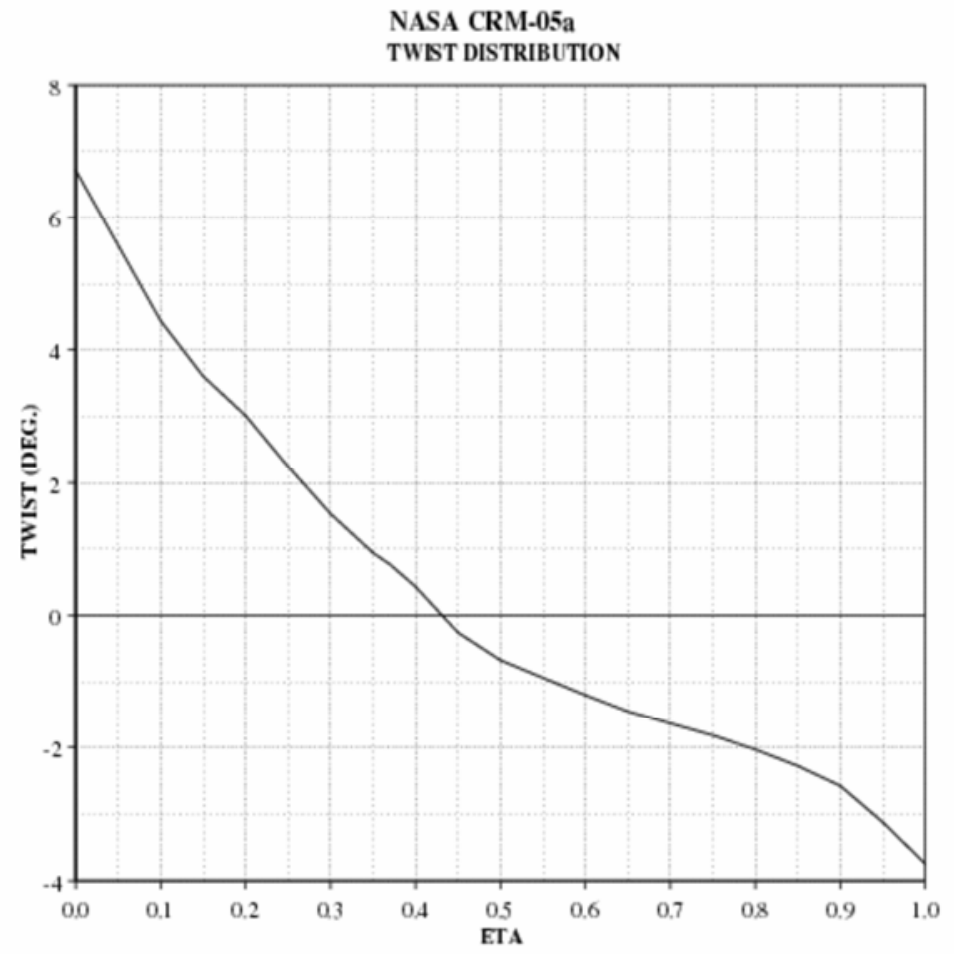

Figure 6: Twist Distribution of the CRM Wing. 


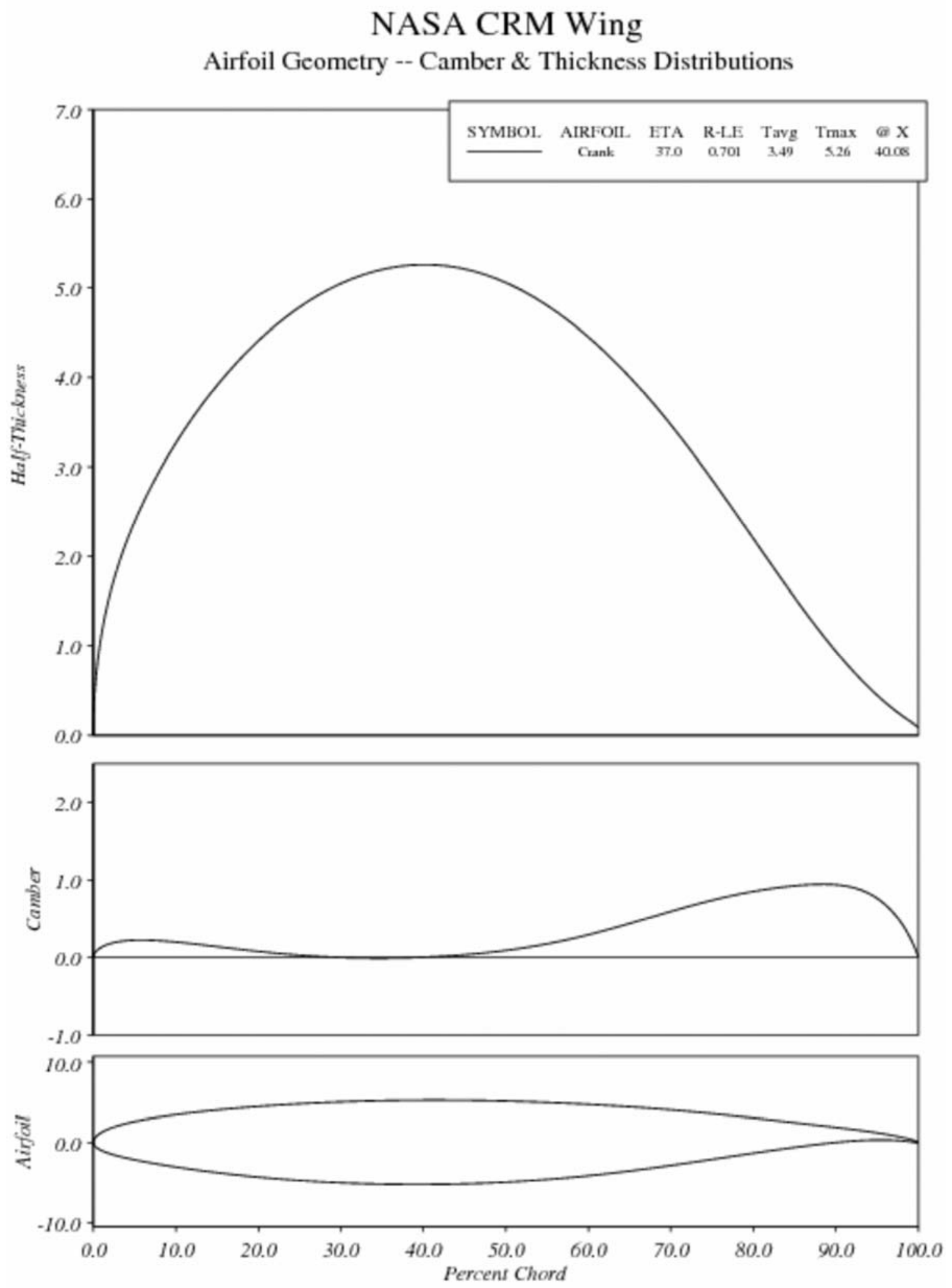

Figure 7: Airfoil Characteristics at the Yehudi Break Station of the CRM Wing. 


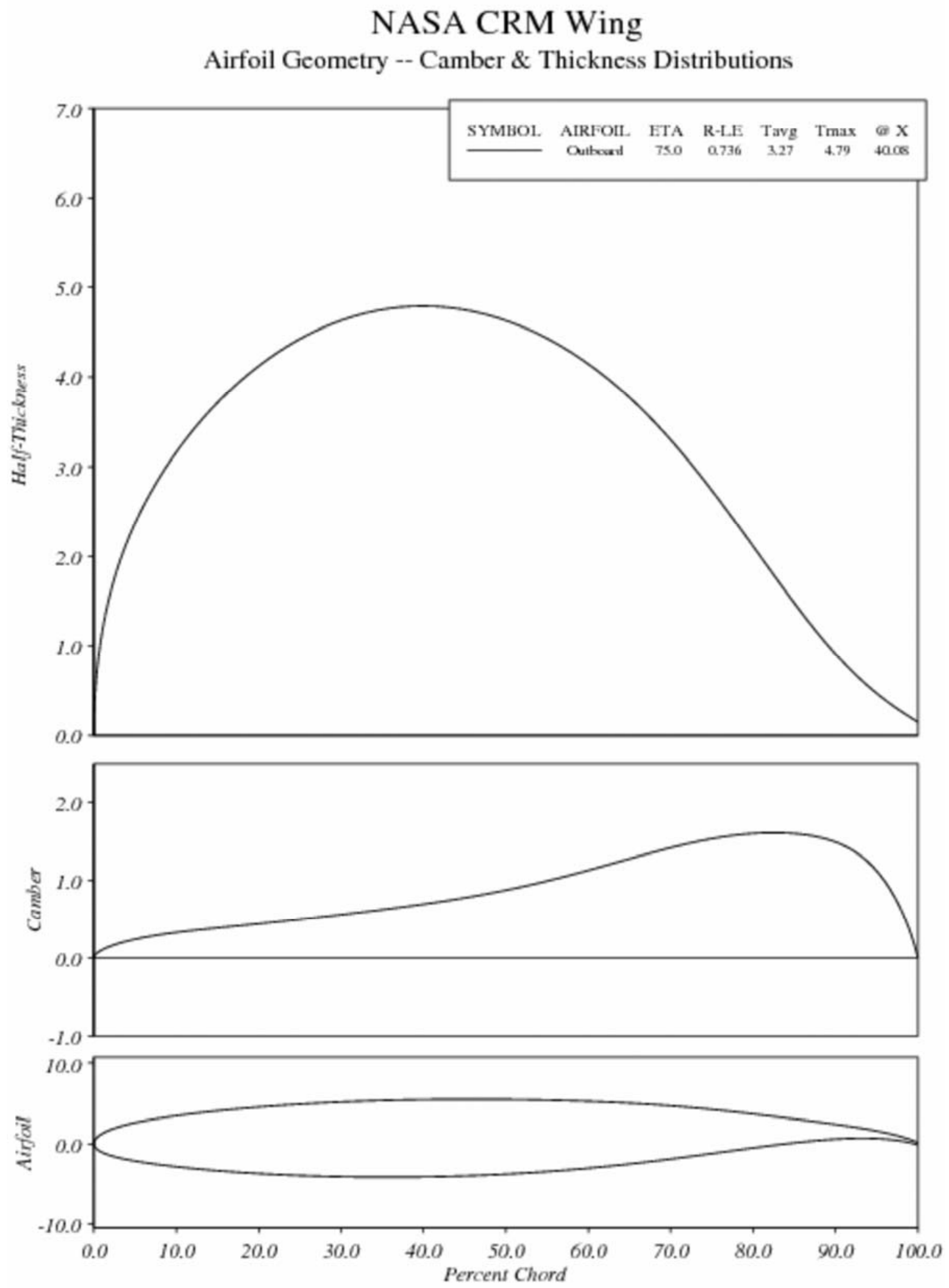

Figure 8: Airfoil Characteristics at an Outboard Station of the CRM Wing. 


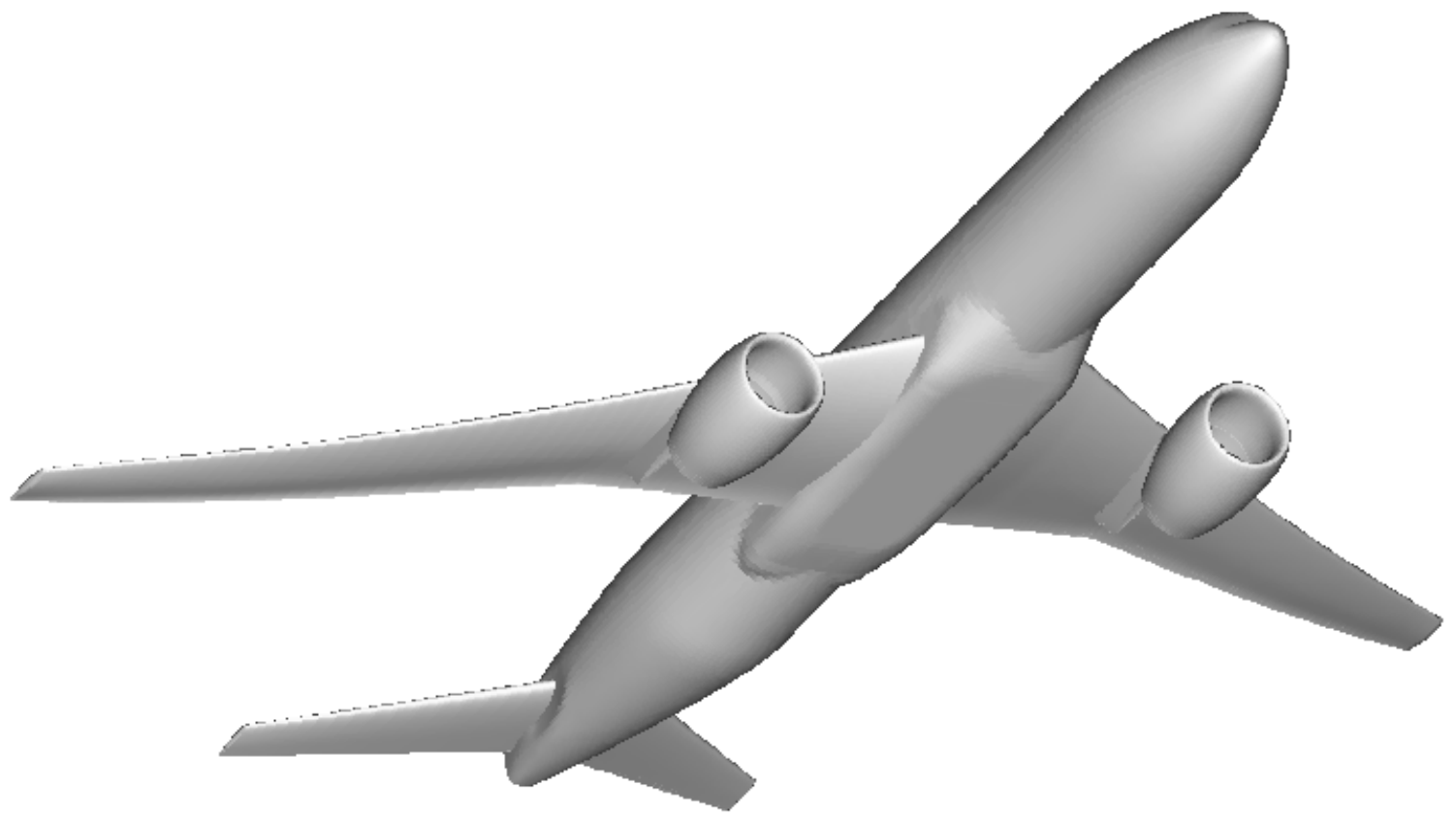

Figure 9: CRM Wing/Body/Nacelle/Pylon/Horizontal-Tail Configuration.

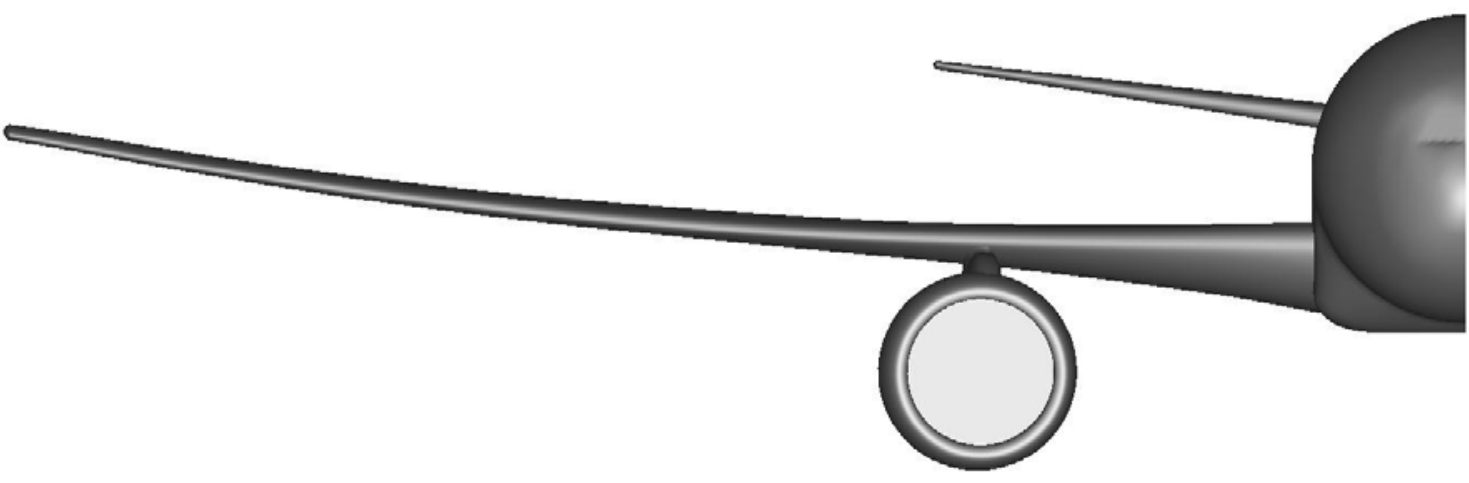

Figure 10: Front View of the CRM showing the Large-Diameter Flow-Through Nacelle. 


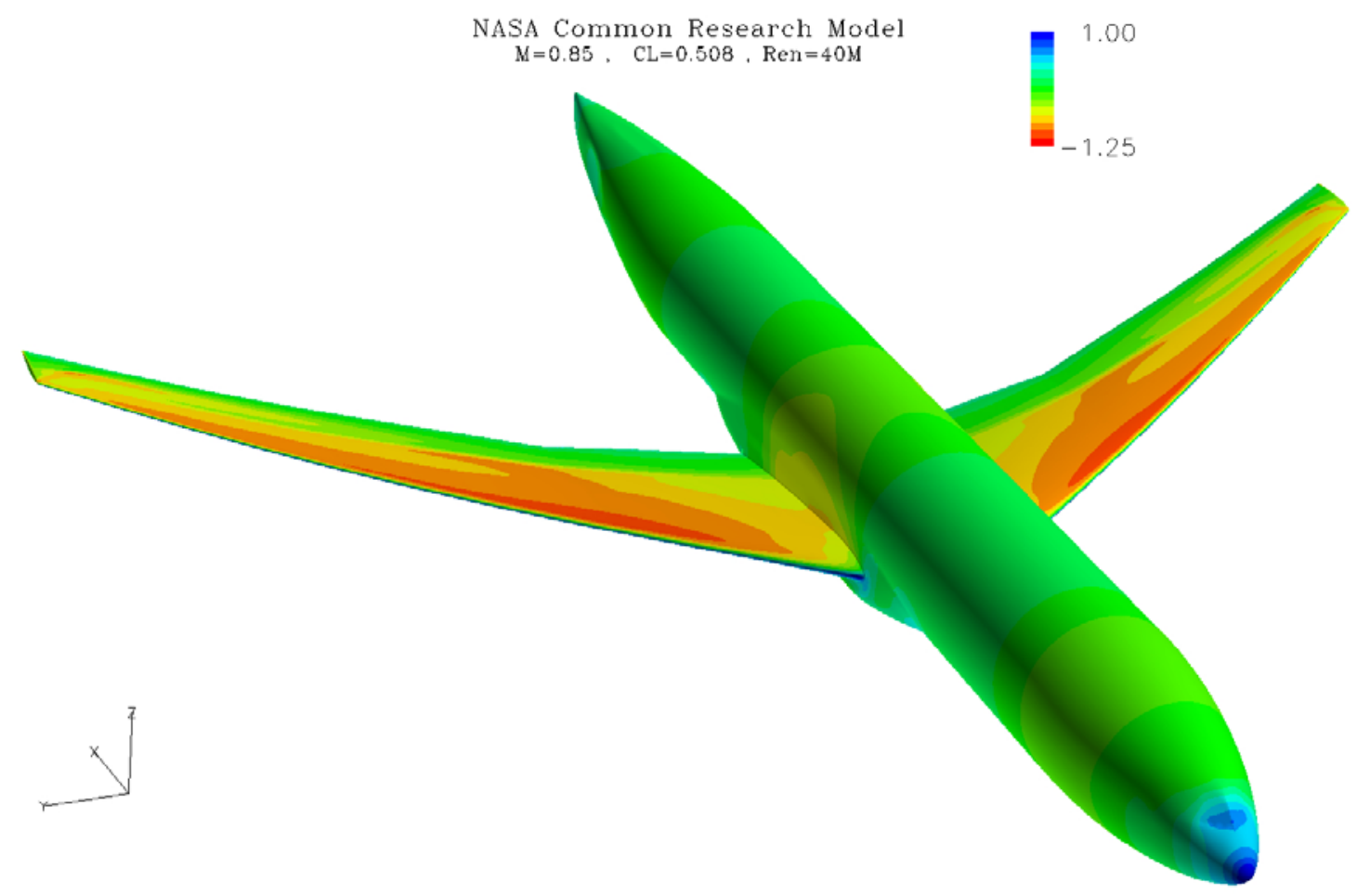

Figure 11: OVERFLOW Isobars of the CRM Wing/Body at the Design Point.

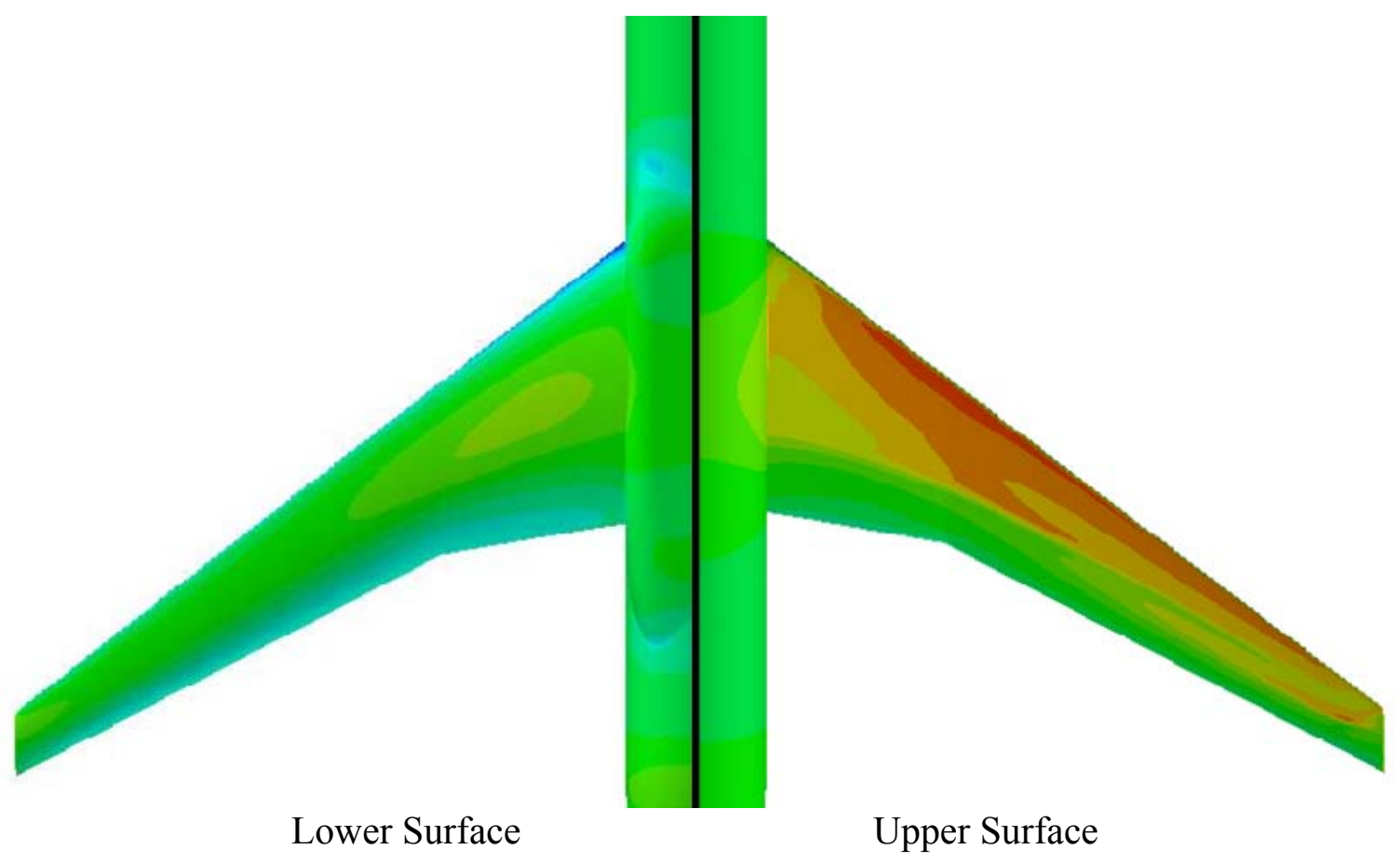

Figure 12: OVERFLOW Isobars of the CRM Wing/Body at the Design Point. 


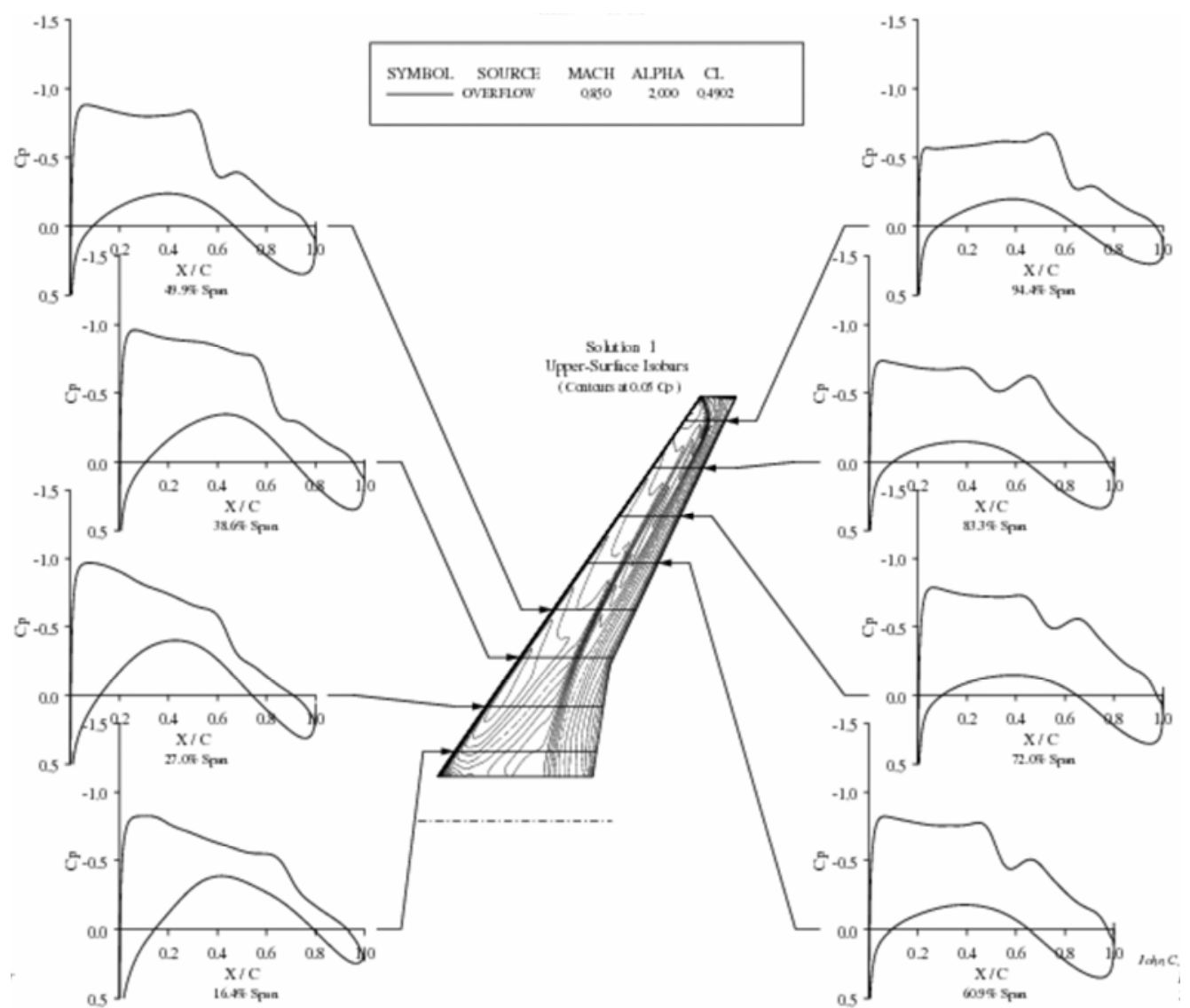

Figure 13: OVERFLOW Wing Pressure Distributions of the CRM Wing/Body.

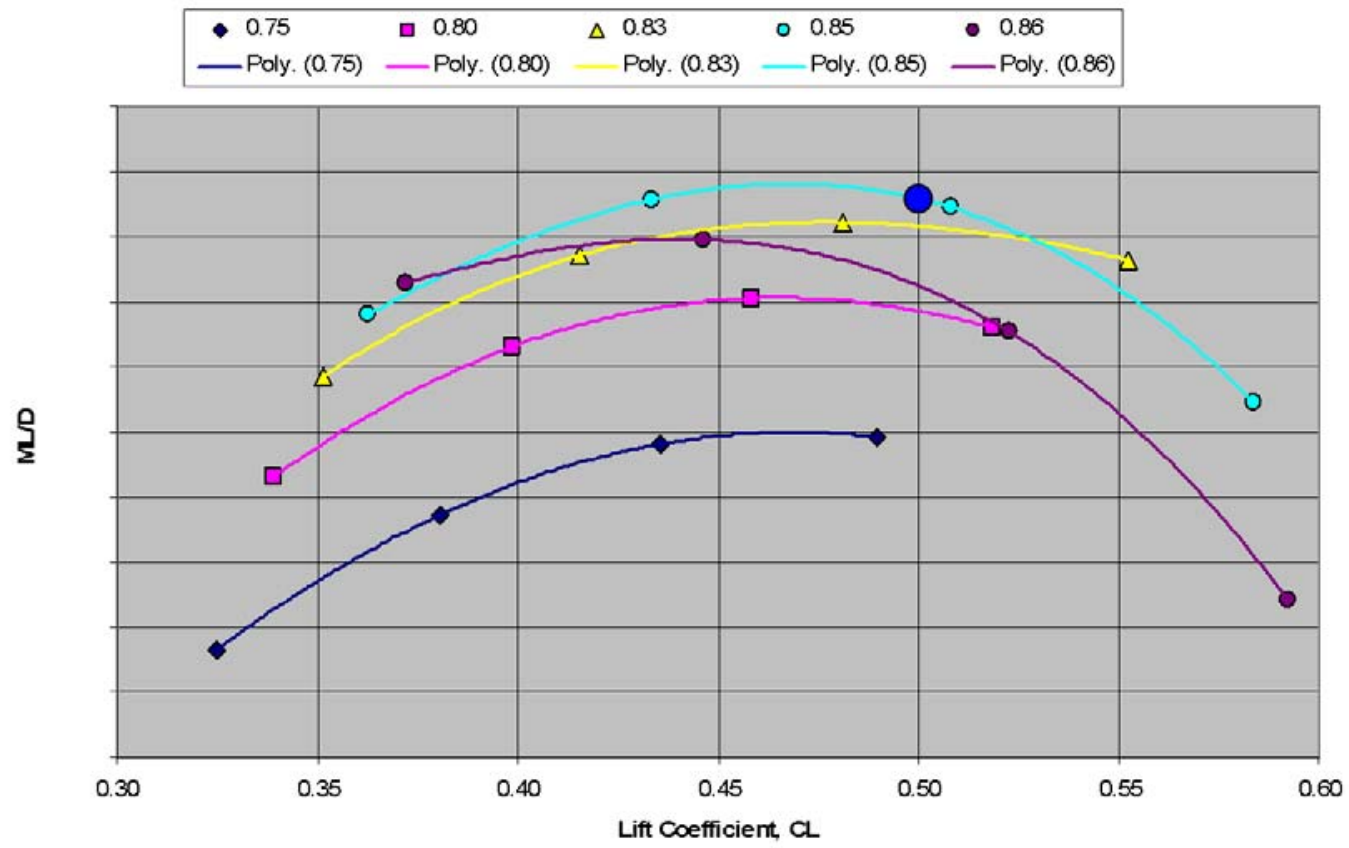

Figure 14: OVERFLOW ML/D Trends for the CRM Wing/Body. 


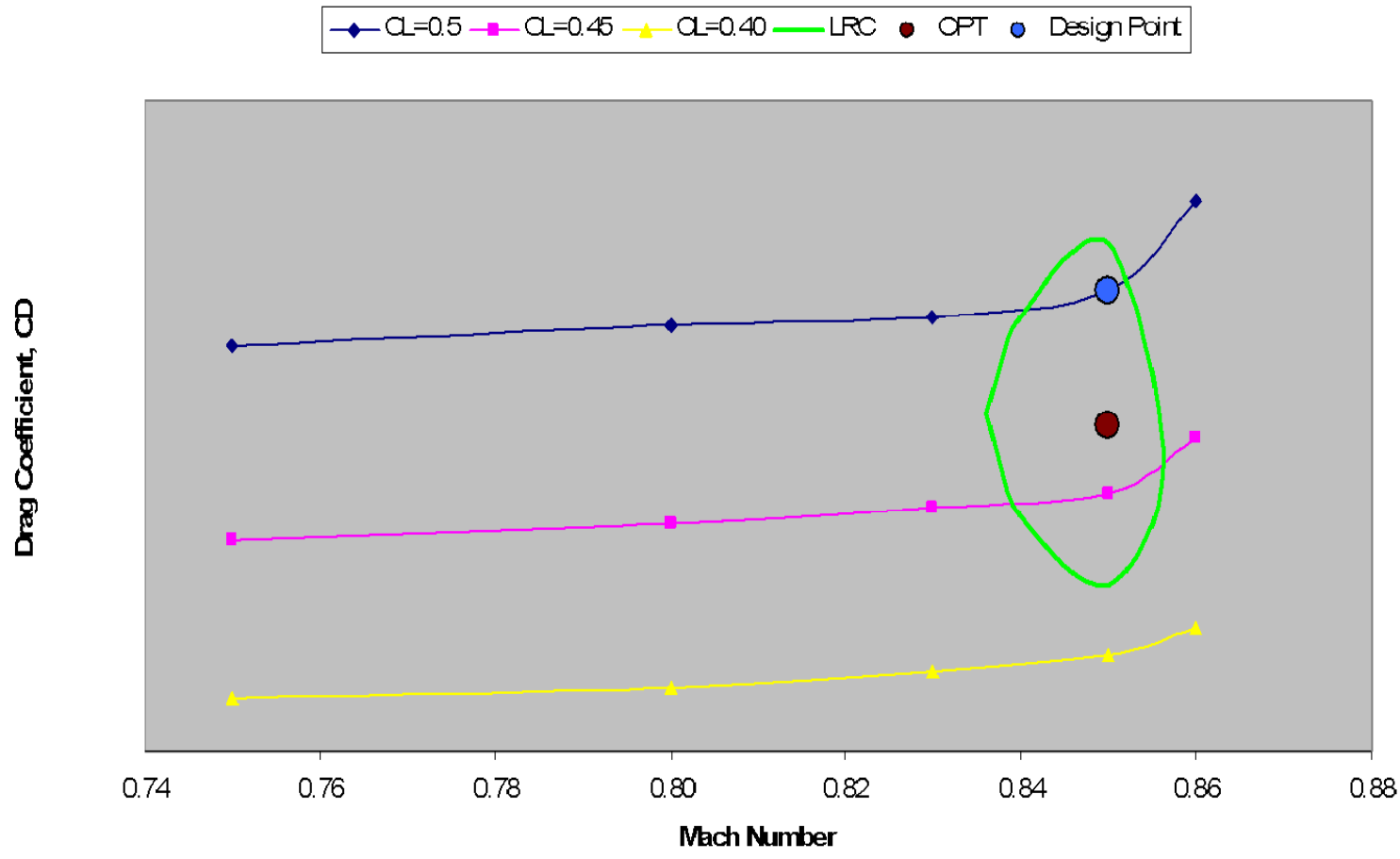

Figure 15: OVERFLOW Drag Rises for the CRM Wing/Body.

- OPT —LRC o Design Point

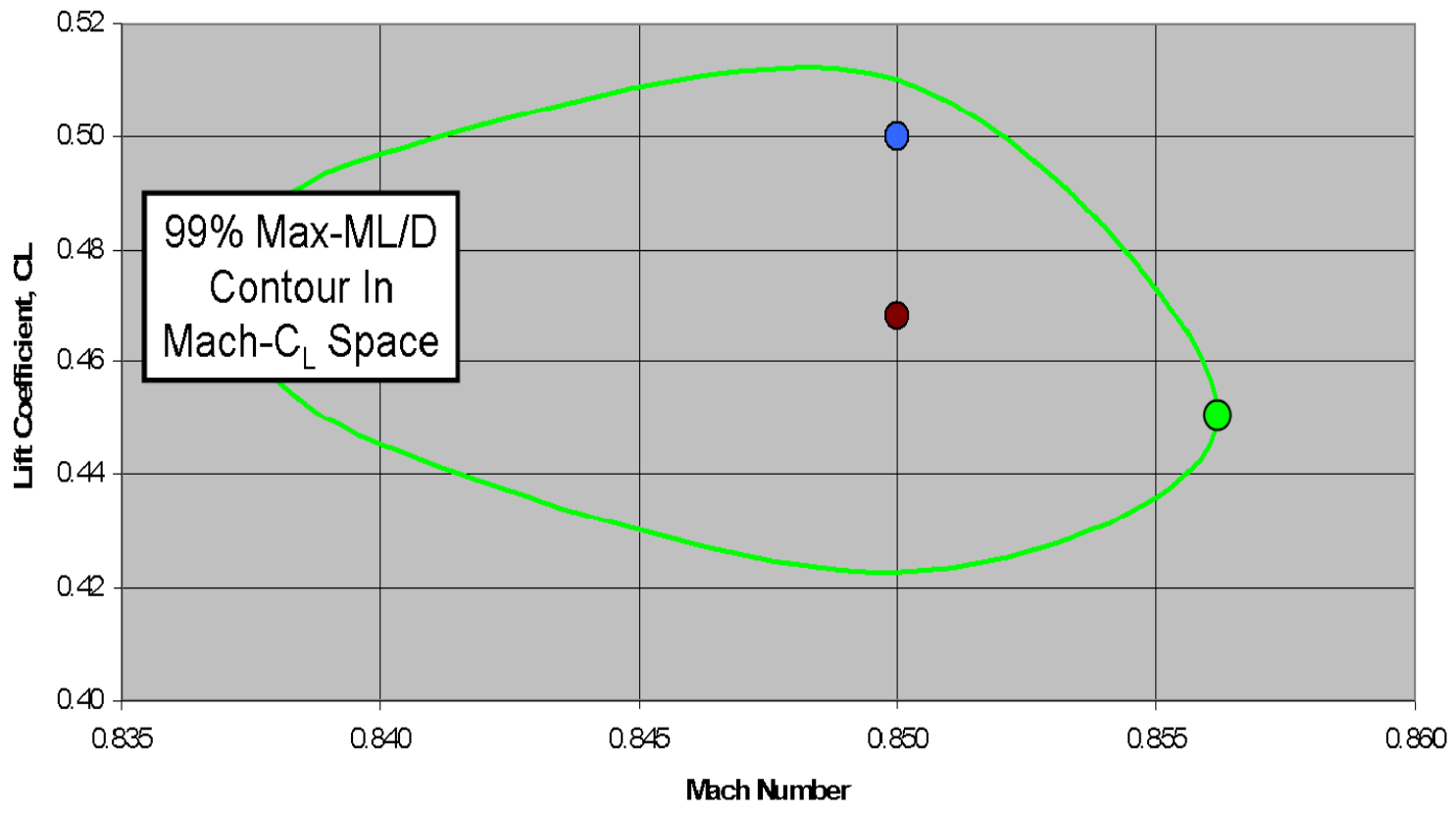

Figure 16: Contour of 99\% Max-ML/D for the CRM Wing/Body. 


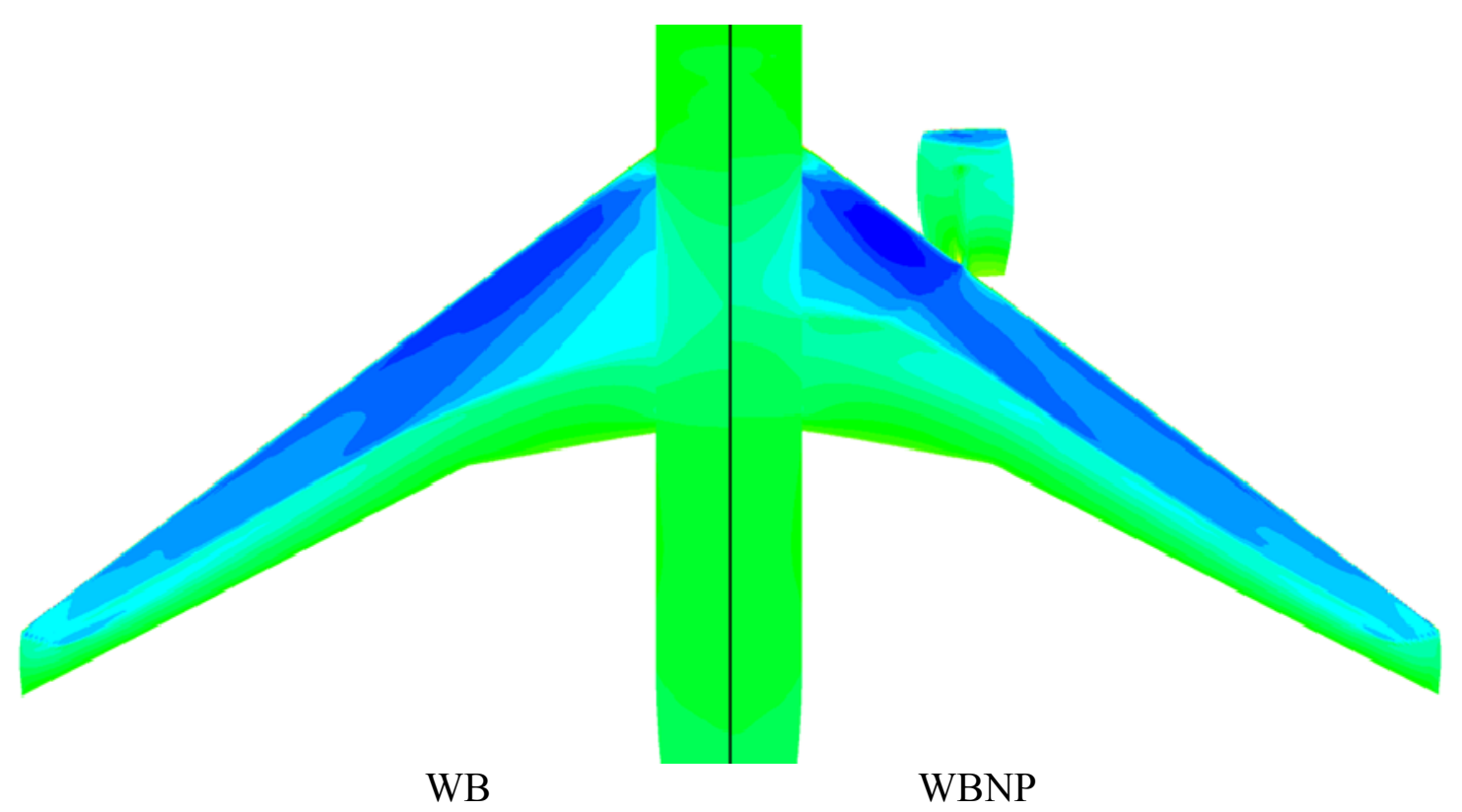

Figure 17: TRANAIR Results of Nacelle-Pylon Effect on Wing Upper-Surface Isobars.

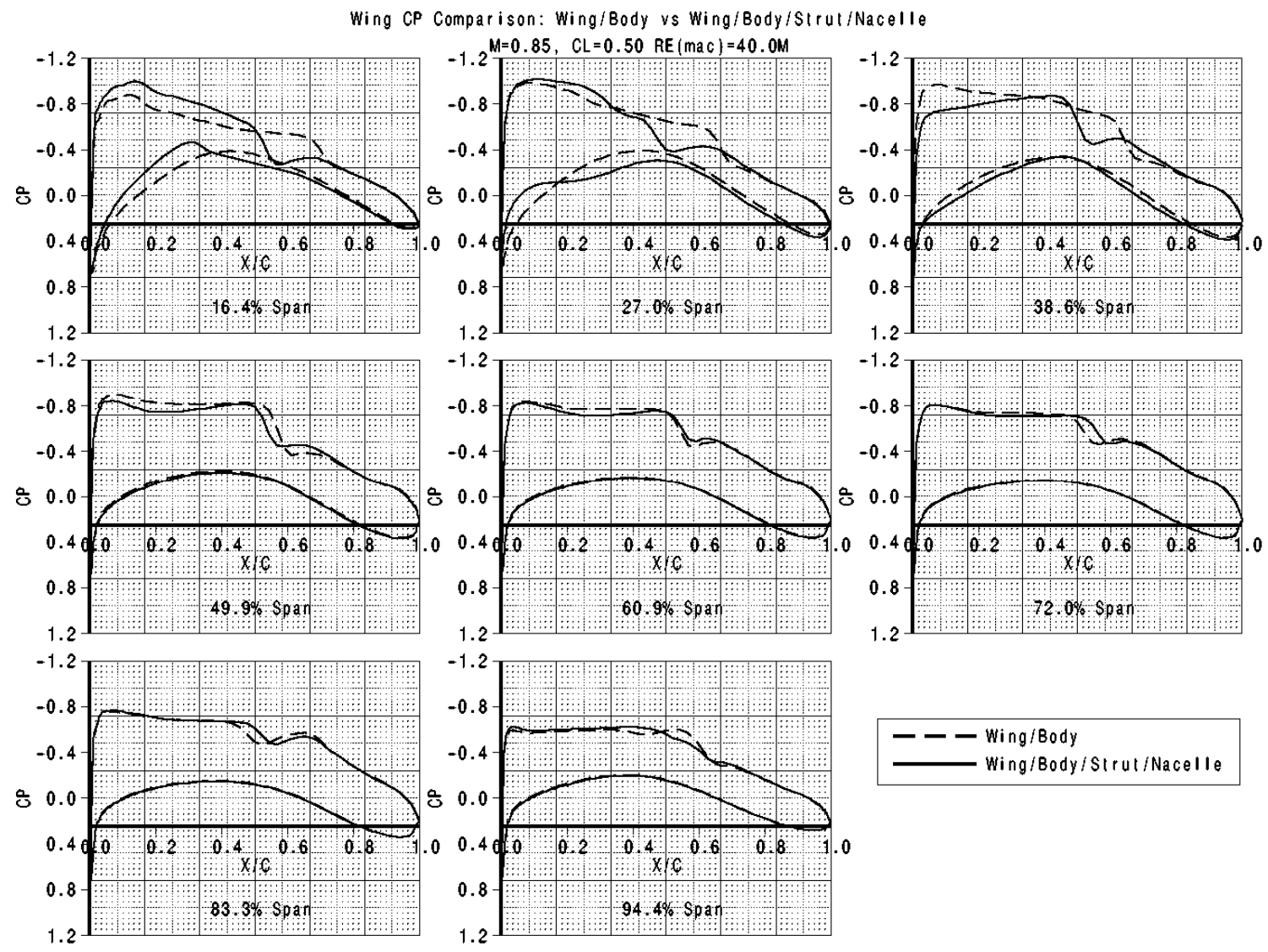

Figure 18: TRANAIR Results of Nacelle-Pylon Effect on CRM Wing Pressures. 


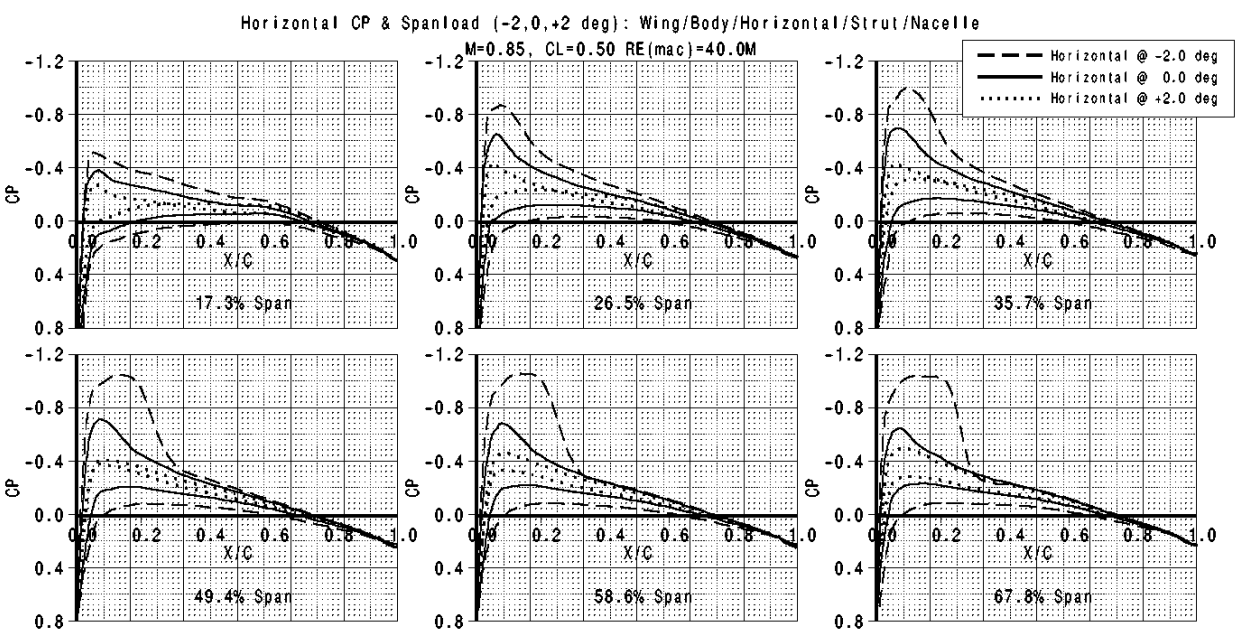

Figure 19: TRANAIR Results of CRM Horizontal-Tail Pressures.

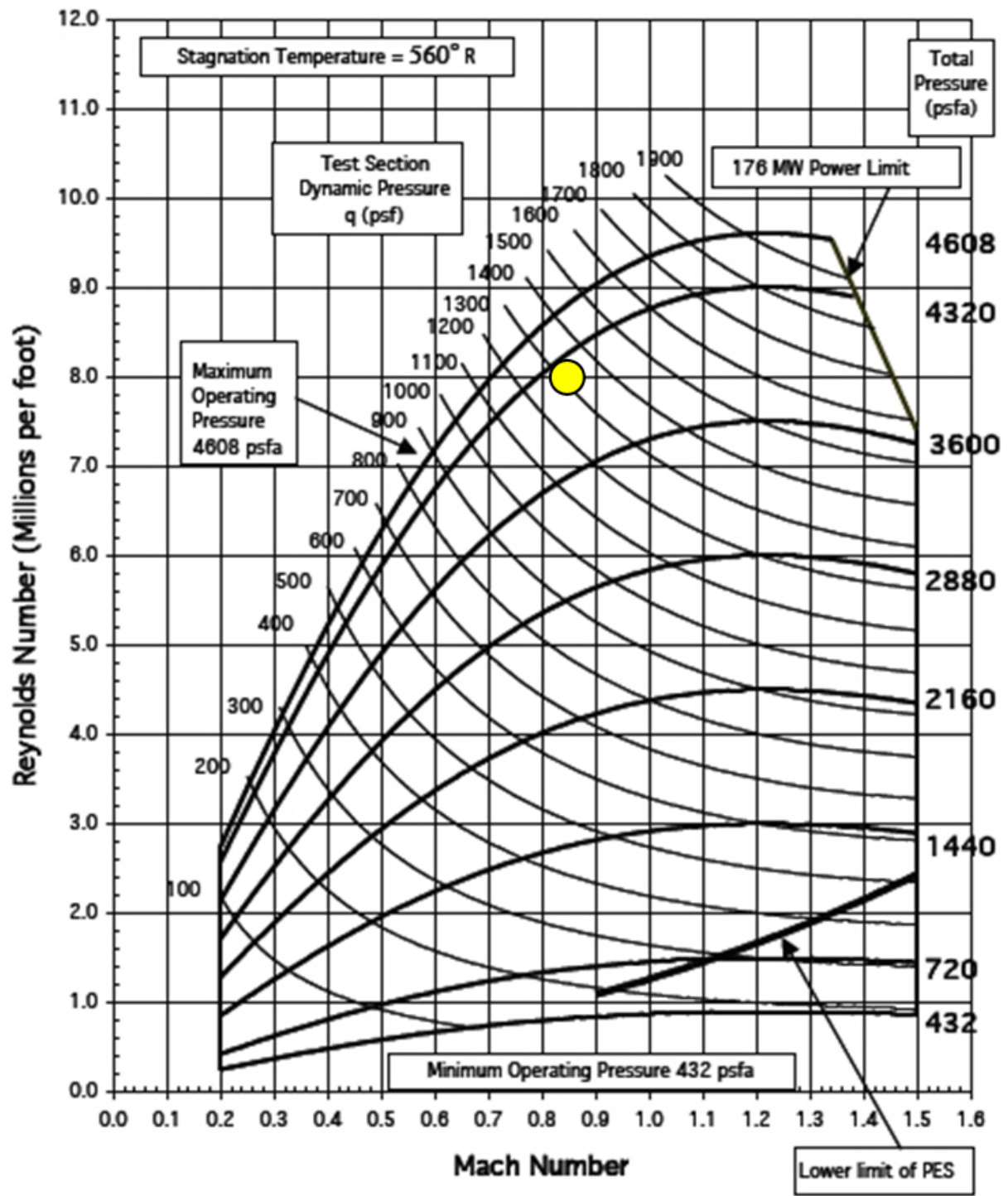

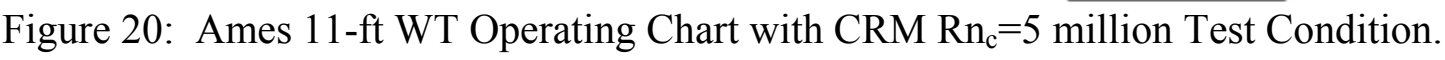




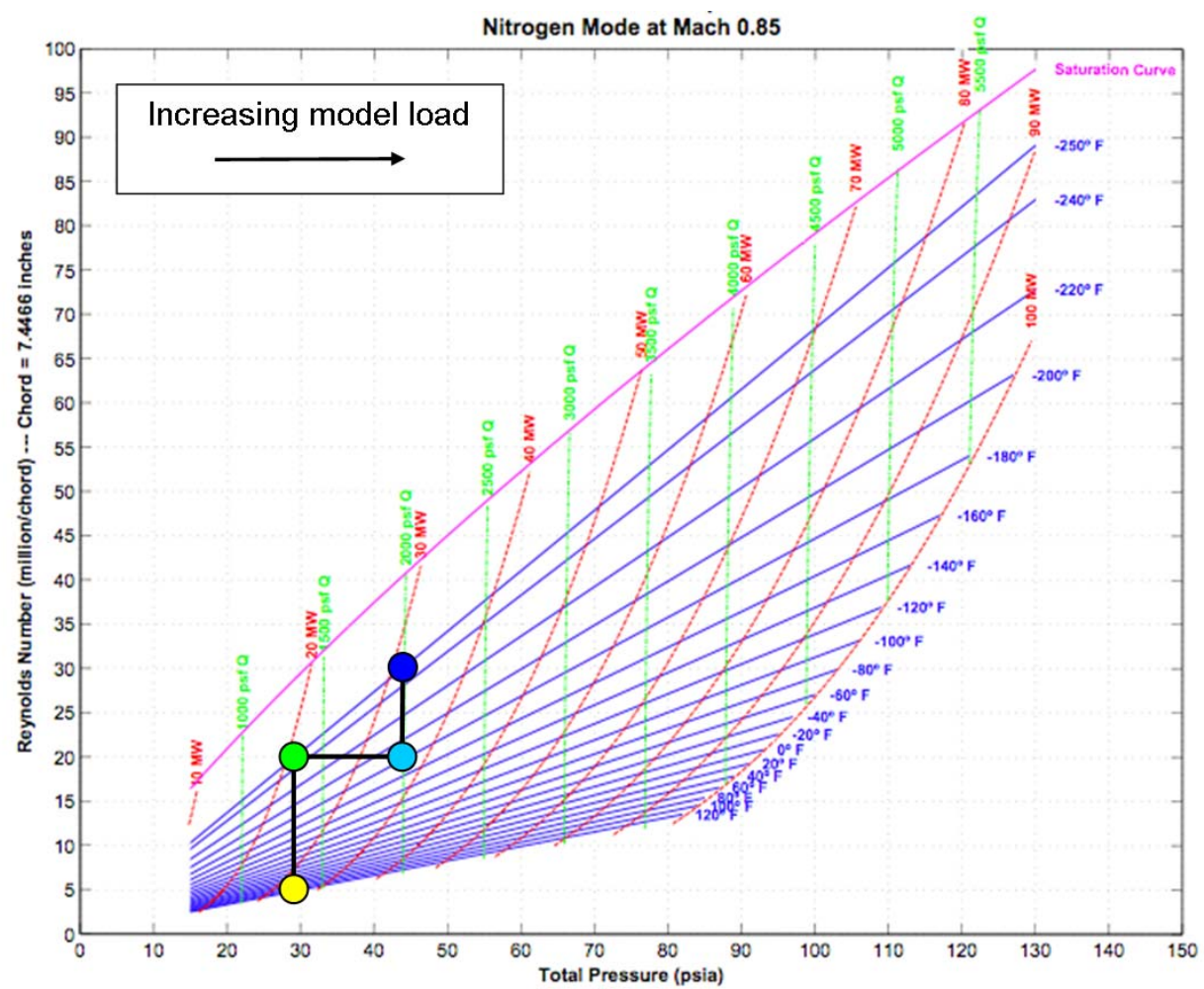

Figure 21: NTF Operating Chart with CRM Test Condition Range.

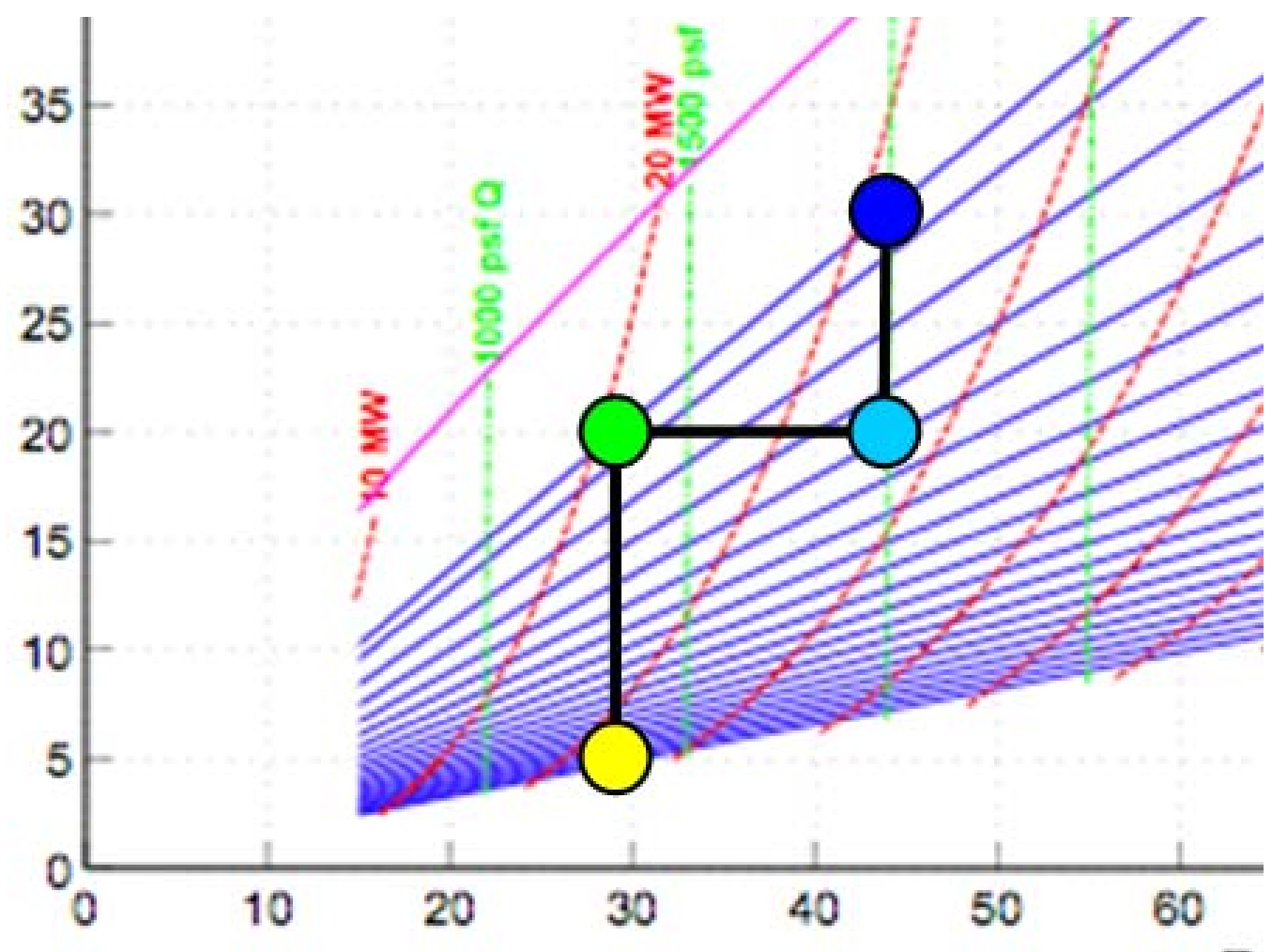

Figure 22: Close-Up View of Figure 21 better showing CRM Test Condition Range. 